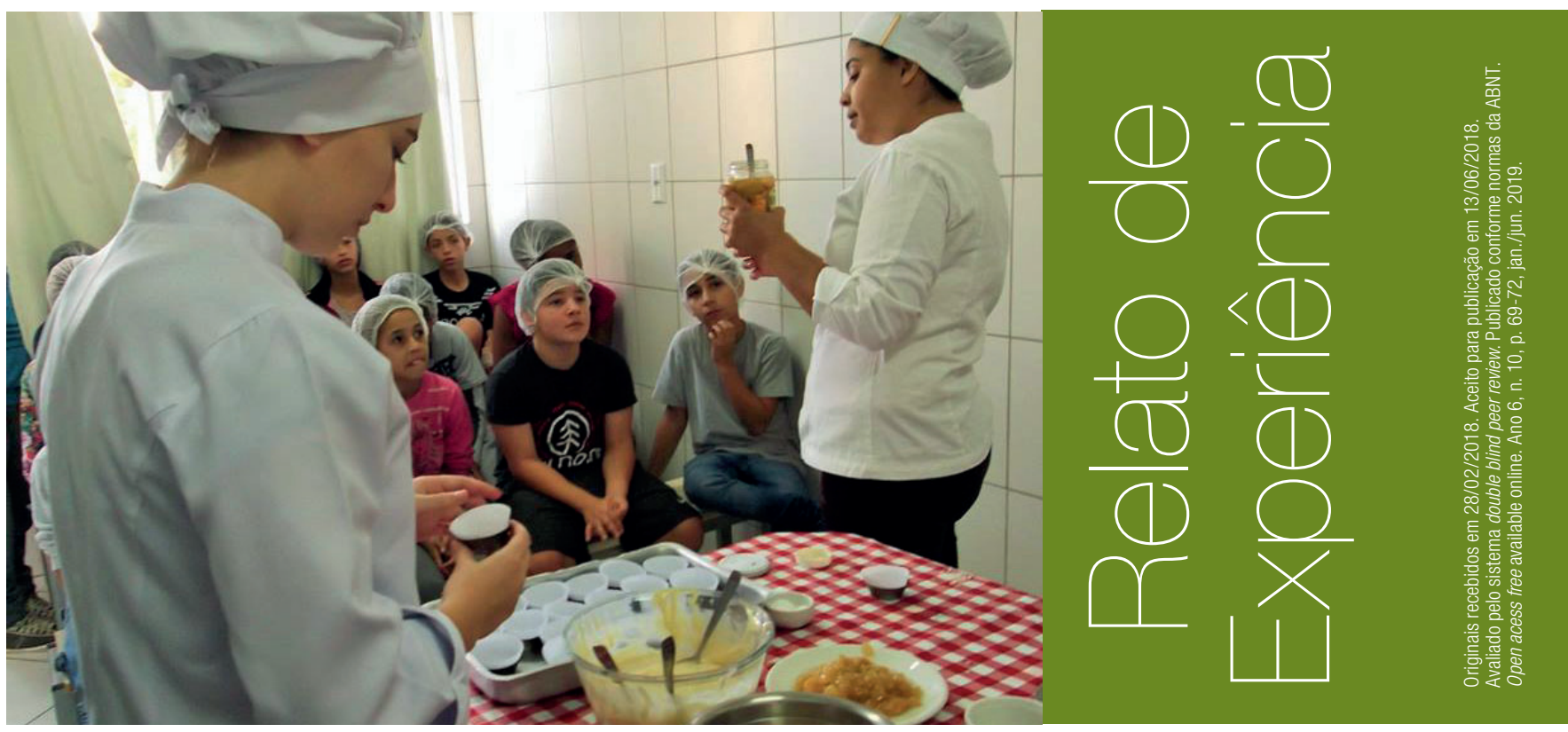

\title{
Alimentação e sustentabilidade: nossas frutas ${ }^{1}$
}

Fernando Goulart Rocha - fernandogr@ifsc.edu.br ${ }^{2}$

Alice N. N. Southgate - alicen@ifsc.edu.br ${ }^{3}$

Fabiana M. Amaral - fabiana@ifsc.edu.br ${ }^{4}$

\section{RESUMO}

0 Brasil possui grande variedade de espécies frutíferas nativas com importante potencial gastronômico e tecnológico. Entretanto, parte da biodiversidade brasileira de frutas é desconhecida da população devido à substituição das variedades nativas por outras de maior apelo comercial. Diante desse quadro, o projeto de extensão pretendeu promover a redescoberta e a valorização da biodiversidade de frutas nativas brasileiras de ocorrência em Santa Catarina por meio de 12 oficinas teórico-práticas em três instituições públicas de ensino no município de Florianópolis.

\section{PALAVRAS-CHAVE}

Alimentação. Frutas nativas. Santa Catarina.

\footnotetext{
1 Projeto de extensão executado com recursos do edital APROEX n.03 - PROEX 09/ 2016.

2 Doutor em Geografia. Professor do IFSC - Câmpus Florianópolis - Continente.

3 Mestre em Turismo e Hotelaria. Professora do IFSC - Câmpus Florianópolis - Continente.

4 Doutora em Química. Professora do IFSC - Câmpus Florianópolis - Continente.
} 


\section{ABSTRACT}

Brazil has a great variety of native fruit trees with a gastronomic and technological potential. However, part of the Brazilian fruits biodiversity still unknown by the population due to the substitution of native varieties for others of greater commercial appeal. In view of this situation, these project aimed to promote the rediscovery and valorization of Brazilian native fruit biodiversity occurring in Santa Catarina State through 12 theoretical-practical workshops, in three public educational institutions in the city of Florianópolis.

\section{KEYWORDS}

Alimentation. Native fruits. Santa Catarina State.

\section{Relato de experiência}

0 Brasil possui grande variedade de frutíferas nativas com importante valor nutricional, além de potencial gastronômico e tecnológico. Entretanto, parte da biodiversidade brasileira de frutas é desconhecida da população devido à substituiç̧ão das variedades nativas por outras de maior apelo comercial. A superação desse quadro desfavorável é desejável e possível, desde que sejam realizadas ações com vistas à valorização, reconhecimento e reinserção na dieta da população das variedades de frutas que constituem o patrimônio alimentar do país. Em vista disso, o projeto de extensão em tela, alinhado à missão de formação para a cidadania do Instituto Federal de Santa Catarina (IFSC), pretendeu promover a redescoberta e a valorização da biodiversidade de frutas nativas brasileiras de ocorrência no nosso Estado.

As atividades de extensão foram realizadas com aproximadamente 250 alunos do $4^{\circ}$ e $5^{\circ}$ ano do ensino fundamental de três instituições de ensino estabelecidas no Município de Florianópolis: uma escola pública estadual (Escola de Educação Básica Júlio da Costa Neves, no bairro Costeira do Pirajubaé), um centro de atendimento a crianças e adolescentes em situação de vulnerabilidade social (Projeto Cevahumos, no bairro Abraão), e uma escola pública federal (Colégio de Aplicação da Universidade Federal de Santa Catarina/UFSC, no bairro Trindade).

A intervenção com os estudantes foi realizada por meio de oficinas teórico-práticas organizadas da seguinte maneira: no primeiro momento os extensionistas apresentavam por meio de ilustrações ou espécimes in natura exemplos de frutíferas nativas do Brasil de ocorrência no Estado de Santa Catarina: araçá, butiá, goiaba serrana e jabuticaba. A apresentação destacava, entre outros aspectos, a dispersão geográfica, as características fisionômicas, as propriedades nutricionais e sensoriais das frutas. Em seguida, os estudantes eram divididos em grupos e fazia-se uma dinâmica de perguntas e respostas com o uso de um dado e um tabuleiro retangular no qual os alunos eram as próprias peças do jogo.

A parte prática envolvia o preparo de uma produção gastronômica sob formato de aula demonstrativa, com 0 emprego de alguma fruta nativa como matéria-prima. Ao término da atividade era distribuído aos participantes porções da preparação feita para que fossem avaliadas sensorialmente. Para a avaliação, solicitava-se aos alunos colocassem em um recipiente um botão de camisa com a cor que melhor representasse a percepção que tiveram sobre o produto: azul (gostei), amarelo (gostei pouco), vermelho (não gostei). Ao final do encontro, entregava-se aos alunos uma cartilha com passatempos e receitas com uso de frutas nativas elaboradas pelos extensionistas.

As oficinas foram desenvolvidas em turmas de até 25 alunos, com idades entre 9 e 11 anos. Nas primeiras experiências, optou-se pela identificação das frutas por meio de ilustrações e 0 levantamento das espécies conhecidas pelos alunos. Esse tipo de abordagem, entretanto, foi substituído mais tarde por apresentar aos alunos frutas in natura, haja vista a dificuldade de os alunos as reconhecerem por meio das figuras. Além disso, optou-se ao longo dos encontros por fazer um recorte mais específico das frutas, com abordagens em três sentidos: características sensoriais e nutricionais, aspectos fisionômicos e dispersão geográfica. 
Sobre a capacidade de identificas as espécies, de maneira geral os alunos eram capazes de reconhecer as frutas nativas apresentadas, sobretudo às de ocorrência no litoral de Santa Catarina. Em contrapartida, a goiaba-serrana (Acca sellowiana), por questão de dispersão restrita às áreas mais elevadas do Planalto de Lages e de São Joaquim, foi a fruta menos identificada espontaneamente pelos estudantes.

A maioria dos alunos afirmou ter conhecido alguma das frutas nativas por meio de parentes e amigos que a cultivavam em quintais ou pomares. Não houve registro de situações em que os participantes apontaram para o consumo diário ou a compra das referidas frutas em feiras ou supermercados, muito embora seja possível encontrar uma ou outra espécie à venda, durante a safra, no comércio local.

A atividade com uso de jogo de tabuleiro com tarefas em cada casa (Figura 1) mostrou-se motivadora e cumpriu 0 objetivo de facilitar 0 aprendizado. Atividades lúdicas com alunos menores parecem reforçar a compreensão do tema na medida em que pressupõe relacionar dados e organizar informações a fim de que possam sistematizar o conhecimento.

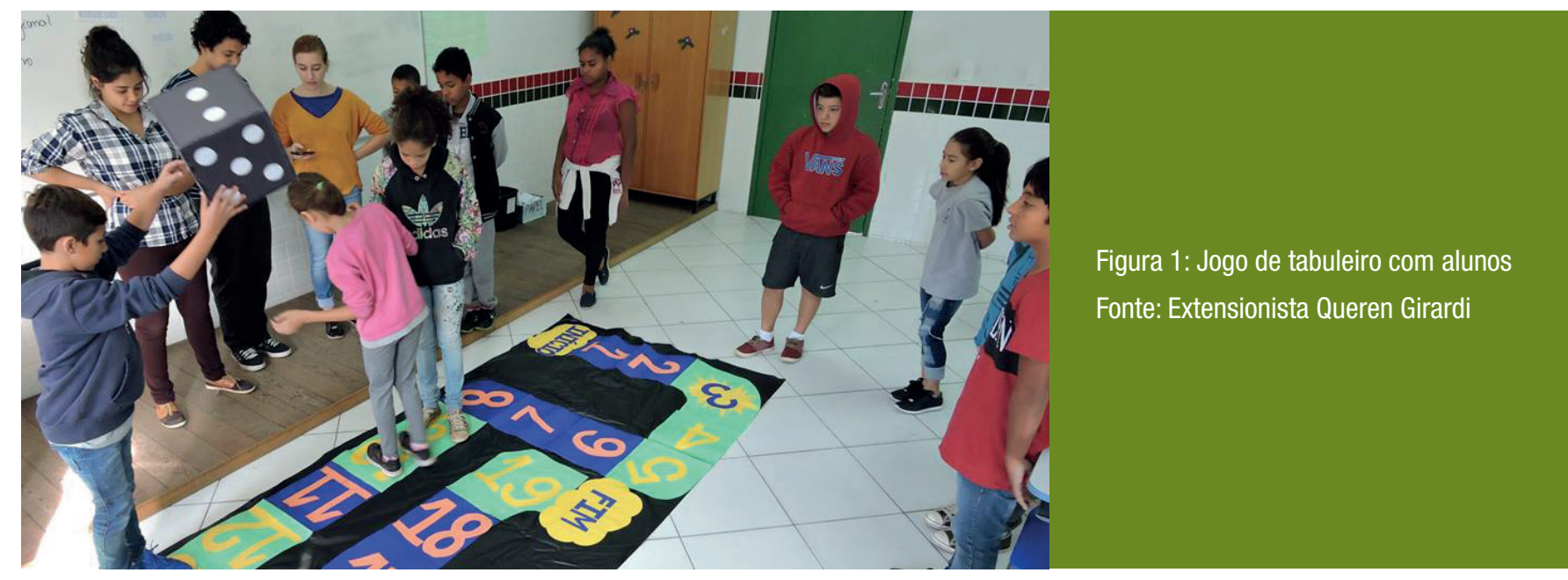

Em relação às oficinas práticas, a experiência de degustação de preparações com 0 uso de insumos regionais (Figura 2) mostrou-se adequada ao propósito de reaproximar os alunos das características sensoriais das frutas locais, ao mesmo tempo em que permitiu avaliar a aceitabilidade das preparações pelos participantes. Como resultado, mais de $90 \%$ dos estudantes conhecia pelo menos uma das frutas utilizadas nas oficinas, e mais de $80 \%$ deles aprovaram sensorialmente os produtos que consumiram.

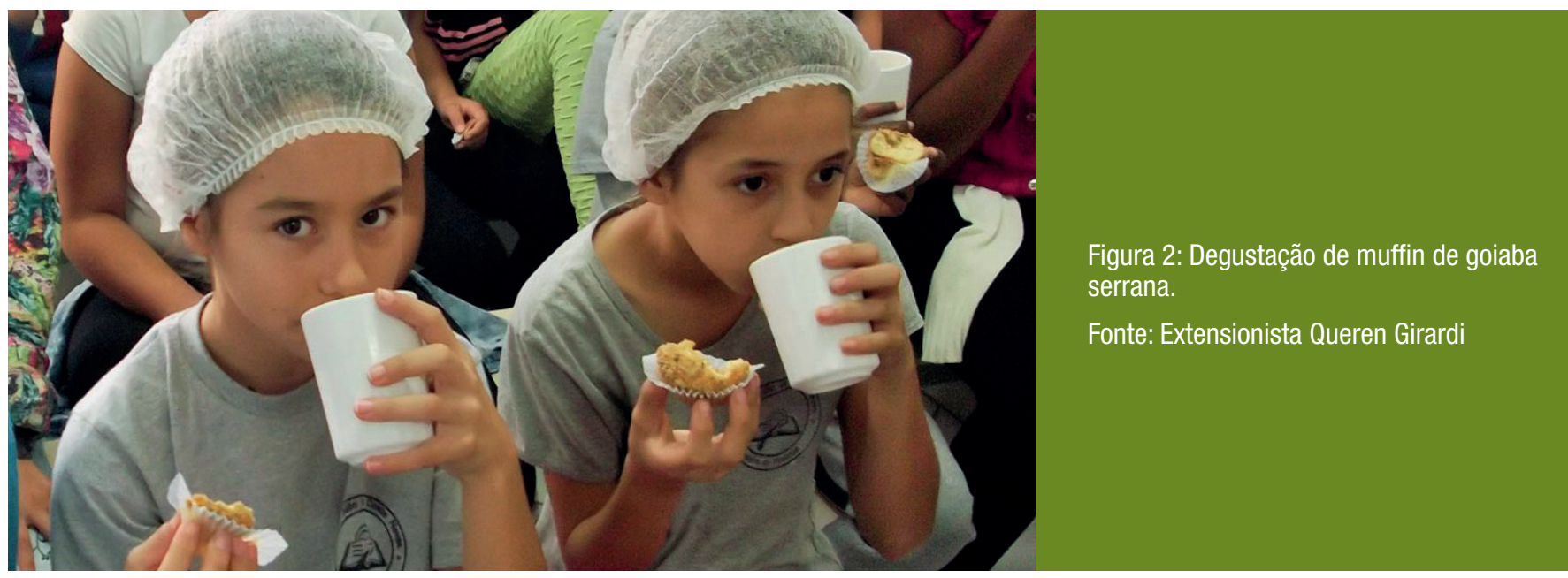

Na experiência e avaliação sensorial das preparações, percebeu-se, entre outros fatores, 0 seguinte: a) crianças são capazes de influenciar uma às outras de maneira positiva ou negativa em relação à experiência sensorial. Em situações em que uma ou mais crianças declarava 
reprovar a preparação, outras imediatamente também a reprovavam. 0 inverso também acontecia: para uma mesma preparação, em grupos em que havia uma ou mais manifestação de aprovação, os demais eram influenciados pela opinião; b) quando desconhecida a fruta apresentada, crianças parecem associar o sabor da fruta a outra por eles conhecida. Assim, por exemplo, os estudantes confundiam nas preparações o gosto característico do butiá por banana, ou da jabuticaba por morango; c) a estética do produto (tamanho, cores, formas e confeitos) e 0 tipo de apresentação (envase, empratamento e uso de utensílios de mesa específicos para degustação) influenciaram, na maioria das vezes, a avaliação sensorial pelos participantes. Nesse sentido, para as crianças, provar o milkshake de butiá em um copo é uma experiência diferente (menos interessante) de experimentá-lo em uma taça; do mesmo modo, um bolo de iogurte com cobertura de jabuticaba, envolto a um guardanapo colorido e algum confeito, é mais saboroso que o mesmo produto sem.

Para a dinâmica das oficinas práticas, a proposta foi que os extensionistas elaborassem as preparações junto com os participantes. Para tanto, foram utilizadas salas de apoio ou refeitórios das escolas para disposição de trabalho equipamentos e utensílios de cozinha, além de insumos, para que os alunos acompanhassem o preparo. Para cada dia de oficina foi escolhida uma preparação, a qual foi repetida nos dois turnos de trabalho: matutino e vespertino. $\mathrm{Na}$ primeira oficina do dia eram servidas preparações elaboradas um dia antes da oficina. No turno vespertino, servia-se o preparado no mesmo dia.

A avaliação das oficinas, com o uso de botões coloridos depositados em um recipiente de plástico, foi eficaz e cumpriu o esperado pela equipe de trabalho. Como o propósito era desenvolver metodologias as mais lúdicas possíveis para a participação das crianças nas atividades, optouse por um meio mais divertido para avaliação das oficinas. Os resultados dessas avaliações apontaram para a aprovação majoritária das preparações pelos alunos, reforçando a ideia inicial de que as frutas nativas brasileiras de ocorrência no Estado têm significativo potencial gastronômico. Além disso, indica que a reinserção dessas frutas na dieta da população local é possível desde que haja ações que permitam reaproximar e disponibilizar aos consumidores acesso a tais recursos.

\section{Agradecimentos}

Os autores agradecem aos extensionistas Ana Clara D. Galluzzo, Queren Girardi, Vitor M. Macieira e Franciele 0. Dias, pessoas que muito contribuíram para o sucesso do projeto.

\section{Referências}

ROCHA, F. MORTIMER, F., SOUTHGATE, A. N. N.: MARTELLI, M., GALLUZZO, A. C. D.; GIRARDI, Q. Nossas frutas. Florianópolis: IFSC, 2017, 12 p. 